\title{
AS TRADIÇÕES ALIMENTARES DOS IMIGRANTES POLONESES EM CURITIBA (PR) E REGIÃO METROPOLITANA: SEU LEGADO ÉTNICO E SUA POTENCIALIDADE TURÍSTICO-CULTURAL
}

\author{
The Food Traditions of Polish Immigrants in Curitiba (PR) and \\ Metropolitan Region: its Ethnic Legacy and Tourist-Cultural Potentiality
}

\author{
Marcos Roberto PISARSKI JUNIOR \\ Universidade Estadual de Goiás \\ marcos.pisarski@gmail.com \\ https://orcid.org/0000-0002-8384-7420 \\ Silvana do Rocio de SOUZA \\ Universidade Federal do Paraná \\ silvanarcsouza@hotmail.com \\ https://orcid.org/0000-0003-0145-3303
}

\begin{abstract}
RESUMO: Este trabalho tem o objetivo de apresentar as tradições alimentares dos imigrantes poloneses e seus descendentes, como parte do patrimônio cultural desse grupo étnico, e dialogar com o potencial uso desse legado cultural como mecanismo de contribuição para a formação de atrativos turísticos para a cidade de Curitiba - PR e sua região metropolitana. Para este trabalho, foi utilizada uma revisão bibliográfica exploratória em referências que tratam da imigração e identidade cultural do imigrante polonês na região, além de contribuições de referenciais do turismo para o embasamento técnico. No decorrer do trabalho, é possível observar alguns elementos da imigração e fixação dos poloneses na região de Curitiba - PR, como o fato de terem sido alocados às margens da cidade, que atrapalharam o seu potencial turístico. Entretanto, é observado que esses problemas podem ser resolvidos através da adaptação a rotas turísticas do tipo rural, onde se pode trabalhar com as comunidades locais.
\end{abstract} PALAVRAS-CHAVE: Tradições Alimentares; Cultura Polonesa; Turismo Gastronômico; Patrimônio Gastronômico.

\begin{abstract}
This paper aims to present the food traditions of Polish immigrants and their descendants, as part of the cultural heritage of this ethnic group, and to dialogue with the potential use of this cultural legacy as a contribution mechanism for the formation of tourist attractions for Curitiba - PR and its metropolitan region. For this work, an exploratory bibliographic review was used in references
\end{abstract}


related to immigration and cultural identity of the Polish immigrant in the region, in addition to contributions from tourism references for the technical basis. During the work it is possible to observe some elements of immigration and settlement of Poles in the region of Curitiba - PR, such as the fact they have been allocated to the city margins, which hindered its tourist potential. However, it is observed that these problems can be solved by adapting to tourist routes of the rural type, where one can work with the local communities. KEYWORDS: Food Traditions; Polish Culture; Gastronomic Tourism; Gastronomic Heritage.

\section{INTRODUÇÃO}

A gastronomia, além de um elemento que expressa de forma material e imaterial a cultura e as tradições de um grupo, pode ser considerada segmento de turismo relacionado ao turismo cultural. Esse segmento ocupa cada vez mais papel de destaque como elemento de atração turística e exerce um poder de decisão na escolha de destinos turísticos.

$\mathrm{Na}$ atualidade, existem diversos exemplos de destinos turísticos que oferecem a sua gastronomia regional como um de seus principais atrativos ou, em algumas ocasiões, como sua característica principal para quem deseja visitar uma cidade ou região.

Entre os tipos da gastronomia, um dos que mais apresentam potencial para contribuir na formação de atrativos turísticos é a gastronomia de receitas típicas de uma região, grupo social étnico ou temático-sazonal, que utiliza elementos culturais locais para ser apresentada.

Esse tipo de gastronomia cultural pode retratar desde complexos temas sociais de época, como um banquete da nobreza europeia ou pratos de momentos de escassez de alimentos para imigrantes e refugiados, até representações de um cotidiano não muito distante - como um simples café colonial.

Porém, dentro do segmento da gastronomia enquanto elemento cultural, a gastronomia como herança cultural ganha uma importância maior devido à sua função social. Entre suas características, o potencial de representação das tradições alimentares de um determinado povo é o que faz com que a gastronomia típica possa trazer uma nova significação para um prato de comida ou para o ato de alimentar-se.

Nesse sentido, este trabalho pretende apresentar e compreender o legado cultural deixado pelos imigrantes poloneses na região de Curitiba (PR) a partir do prisma do patrimônio gastronômico, parte do patrimônio cultural imaterial. Em seguida, serão realizados apontamentos de como é possível a atividade turística utilizar o legado cultural 
alimentar da imigração polonesa como um atrativo turístico.

Para a realização deste trabalho, foi utilizada uma intensa revisão bibliográfica exploratória focada e dividida em dois eixos, sendo o primeiro a respeito de elementos da imigração, cultura e patrimônio, e o segundo sobre aspectos e fundamentos do turismo cultural e da gastronomia.

Dentre os autores trabalhados nesta pesquisa, Adamoski e Krieger (2013), Doustdar (1990), Gluchowski (2005), Iarochinski (2000), Pisarski Junior (2019), Teleginski (2014), Turbanski (2005) e Wachowicz (1972) trabalham com o primeiro eixo: elementos da imigração, cultura e patrimônio.

A respeito do segundo eixo, aspectos e fundamentos do turismo cultural e gastronomia, foram utilizados os autores: Alvarez (2005), Bahl (2004), Beni (1998), Bizinelli, Manosso, Gimenez-Minasse e Souza (2014), Gândara (2008), Gimenes-Minasse (2013), Mascarenhas (2009), OMT (2012), Pires (2005), Poulain (2008), Scarpato (2002) e Schlüter (2003).

Assim, foi possível realizar uma comparação entre os elementos teóricos pesquisados e a realidade atual encontrada no turismo envolvido nesses aspectos culturais.

\section{A IMIGRAÇÃO POLONESA}

A cidade de Curitiba (PR) e sua região metropolitana figuram como uma das regiões que mais receberam fluxo imigratório entre o final do século XIX e o início do século XX em todo o Brasil. Milhares de imigrantes alemães, italianos, poloneses, ucranianos e japoneses se instalaram definitivamente na cidade, fazendo assim uma drástica mudança nas relações sociais e culturais existentes na época (WACHOWICZ, 1972).

No caso da imigração polonesa ao Brasil, esse fenômeno ocorreu a partir do ano de 1869, com a chegada de um grupo de famílias polonesas. Esse grupo se fixou na região do litoral norte do estado de Santa Catarina, como afirma:

Os primeiros representantes do grupo étnico polonês chegaram ao Brasil em 1869. Um grupo de 16 famílias, com aproximadamente 80 pessoas, provenientes da localidade de Siolkowice, região de Opole, província da Silésia, então sob ocupação prussiana, fixou-se numa área de terras da Colônia Príncipe Dom Pedro, próxima à Colônia Itajaí, atual município de Brusque-SC (REIS, 2009, p. 2).

Esse processo foi consequência da situação e condições enfrentadas no cotidiano europeu, que passava por diversas transformações em sua estrutura. Como colocam 
Adamoski e Krieger (2013), questões como a divisão desigual de terras no período pós feudal (onde poucos acumularam extensas porções de terras produtivas e a grande maioria precisou se sujeitar a péssimas condições de trabalho para manter a sobrevivência de sua família, ou migrar para os recém-formados centros urbanos industrializados devido à recente revolução industrial) e o crescimento demográfico, entre outros aspectos socioeconômicos, favoreceram o surgimento das ondas imigratórias europeias para o continente americano e, mais especificamente, para o Brasil.

Por sua vez, a questão da imigração polonesa para o Brasil teve outros elementos que foram mais relevantes para o acontecimento das ondas imigratórias, nos quais se destacou a situação política e nacional polonesa. Como cita Doustdar:

Em fins do século XVIII, a Polônia desapareceu como nação livre e
independente, transformando-se num pedaço de chão da periferia
oriental dos grandes centros de decisão localizados no ocidente da
Europa. Frente a uma Europa que emergia da Revolução Industrial, a
Polônia sofria ainda os efeitos das forças medievais, principalmente
de uma população camponesa feudalizada. Associado a isso, havia
o domínio da ação conjunta de três potências ocupantes: a Áustria, a
Prússia e a Rússia (DOUSTDAR, 1990, p. 76).

Devido a essas questões, a população polonesa iniciou o seu processo imigratório sem pertencer a seu país de origem, que havia deixado de existir enquanto Estado independente, mas sim enquanto nação polonesa, como afirma Iarochinski:

Quando a imigração polaca começou no Brasil, não existia o Estado Polaco, somente a nação. A Polônia, após ter sido um dos maiores países europeus nos séculos XVI e XVII, foi invadida no século dezoito pelos seus três vizinhos, Rússia, Áustria e Prússia. (IAROCHINSKI, 2000, p. 64)

Enquanto ocorriam esses processos sociais no velho continente, no Brasil ocorriam uma série de fenômenos sociopolíticos que contribuíram para que o país fosse um dos principais destinos para os imigrantes poloneses e europeus de uma forma geral.

Com o processo de abolição da escravatura (1850-1888), a mão de obra negra teve que deixar de ser explorada e com isso surgiu uma necessidade para o Estado brasileiro: ter mão de obra qualificada para a produção agrícola nacional. Como é citado por Santos:

O tráfico negreiro, enfim, chegaria ao fim. A reposição de mão-de-obra escrava vinda da África deixaria de existir, e juntamente com ele um dos 
grandes fatores de acumulação lusa no Brasil-Colônia e posteriormente Império. Porém, o tráfico em si não cessa plenamente no Brasil. A rápida expansão da economia cafeeira gerou uma crescente demanda por mão-de-obra (SANTOS, 2008, p. 11).

Por esse motivo, o governo brasileiro investiu na propaganda e viabilizou políticas de incentivo a fim de atrair imigrantes europeus para o território nacional. Como cita Bueno (1996, p. 14-15): "Em busca de mão de obra para as lavouras, as autoridades brasileiras promoveram na Europa uma intensa propaganda sobre a fertilidade das terras brasileiras".

E completa:

Com o intuito de promover a vinda de europeus para o trabalho agrícola nas terras brasileiras, as companhias de imigração divulgavam as vantagens oferecidas pelo sistema de imigração brasileiro. As companhias instaladas em diferentes países ofereciam passagens gratuitas aos emigrantes que quisessem tentar a sorte em outros lugares. A pretensão de organizar o caos reinante nas cidades europeias, decorrente do crescimento populacional, facilitava e impelia a saída dos desempregados, o excedente da população rural, os desclassificados que vagavam nas ruas dos centros urbanos, os velhos e as famílias numerosas (BUENO, 1996, p. 15).

Aliado a isso, um dos maiores interesses dos imigrantes poloneses e demais europeus era o de conquistar seu direito à propriedade, ao trabalho digno, à liberdade e de estar longe de guerras e domínios que devastavam seus meios de vida, como coloca Gritti (2004, p. 33): "Não é difícil imaginarmos quanto era atrativo o Brasil para os camponeses de então, principalmente se considerarmos a pobreza que sofriam antes da emigração".

A partir dessas políticas de incentivo para a mobilização de imigrantes europeus para o Brasil e do grande interesse que foi gerado em terras europeias, ocorreram as ondas imigratórias que transformaram o cenário sociocultural nacional, e, em especial, da região sul do país.

Dentre algumas das mudanças que esses imigrantes proporcionaram estão os aspectos sociais e culturais, sendo a alimentação um dos pontos mais marcantes no qual se observa o legado dos imigrantes em Curitiba até os dias de hoje. Isso se deve ao fato de que, quando essas pessoas deixaram seus países de origem, trouxeram consigo muito mais do que suas bagagens, mas diversos hábitos, costumes e tradições culturais e alimentares, como cita Maciel: 
[...] fizeram com que as populações que se deslocaram levassem com elas seus hábitos, costumes e necessidades alimentares, enfim, todo um conjunto de práticas culturais alimentares. Para satisfazê-las, levaram em sua bagagem vários elementos, tais como plantas, animais e temperos, mas também preferências, interdições e prescrições, associações e exclusões. (MACIEL, 1996, p. 51)

Considerada como uma das cidades mais "polacas" do mundo, até o começo dos anos 2000 a cidade de Curitiba - PR contava com mais de 300 mil habitantes com ascendência polonesa, resultado do grande fluxo migratório desse grupo étnico para a região nos séculos passados (IAROCHINSKI, 2000).

A presença do grupo étnico-cultural dos poloneses influenciou o município em seu desenvolvimento ao longo do século XX, sendo importante na produção de alimentos nas áreas rurais nos arredores da cidade e formando o cinturão verde da região metropolitana de Curitiba, fonte da produção hortifrutigranjeira da região e considerado por Wachowicz "o primeiro cinturão verde organizado por imigrantes no Brasil” (WACHOWICZ, 1988, p. 146).

Além da importância rural, os poloneses e seus descendentes tiveram importância na participação política e técnica durante esse período, tendo vários vereadores, secretários de governo e diretores de órgãos públicos e privados de ascendência polonesa. O principal caso é o de Jaime Lerner, filho de judeus-poloneses, que foi responsável pelo plano diretor de desenvolvimento da cidade de Curitiba nos anos 1960, prefeito municipal nas décadas de 1970 e 1980 e governador do estado do Paraná nos anos 1990.

O campo das artes é outro espaço onde a influência dos poloneses e seus descendentes pode ser notada facilmente, seja nos nomes de dezenas de ruas espalhadas pelo município, no Bosque da Imigração Polonesa, chamado de "Bosque do Papa" devido a visita do então Papa João Paulo II (Karol Wojtyla, polonês), na arquitetura das casas coloniais, ou na literatura, tendo como principal exemplo o poeta e escritor Paulo Leminski, neto de poloneses.

Dessa forma, é possível notar a relevância da influência do grupo étnico-cultural dos poloneses de forma transversal no desenvolvimento do município de Curitiba - PR no século XX, questão que se expande para diversos outros aspectos, como a culinária regional. 


\section{A GASTRONOMIA COMO PATRIMÔNIO CULTURAL}

A gastronomia, como ciência das culturas alimentares, carrega em si um acúmulo histórico de conhecimentos e costumes que são passados de geração em geração. O saber de diferenciar um alimento de um não alimento, o conhecimento empírico trazido pela tentativa e erro de gerações é traduzido na forma de costume alimentar, e nisso é difundido por grupos que se reconhecem em mesmos símbolos culturais.

A comida, fruto desse processo, não é apenas um produto nutricional voltado para o consumo visando a reprodução, como o campo das ciências da saúde busca definir. Ela é o resultado da simbiose de culturas, terroirs, contextos históricos, políticos e geográficos de cada grupo social.

Nesse sentido, Scarpato (2002) define que comida é um artefato cultural, resultado dos conhecimentos e relações culturais com a materialidade de insumos alimentares disponíveis para a produção da comida em si. Assim, como um artefato cultural, a comida e as suas comensalidades são elementos que se relacionam dialogicamente com os indivíduos de um grupo social, fazendo com que pessoas se identifiquem entre si pelo que e como comem (SCARPATO, 2002).

Dessa forma ocorre o processo de popularização de costumes culturais, entre eles, a alimentação. Isso pode ocorrer de forma popular ou de forma dirigida, como afirma Hobsbawm (2008) na obra $A$ origem das tradições, onde aponta que o Estado pode se utilizar de costumes populares (o que pode incluir a alimentação) para criar uma identidade nacional, chamada de tradição cultural.

Esse processo de "burocratização" dos costumes populares pode ser exemplificado com o uso da feijoada como uma tradição cultural brasileira, mesmo sem considerar sua abrangência e origem.

Essas tradições "hobsbawnianas", como fruto da identidade nacional do Estado, são muito perceptíveis quando analisamos os tombamentos de patrimônios culturais históricos (os chamados bens de cal e pedra) realizados no Brasil pelo IPHAN (Instituto do Patrimônio Histórico e Artístico Nacional). Em sua grande maioria, principalmente os bens tombados anteriores à década de 80 , representam a exaltação de estruturas nacionais, famílias tradicionais e forças armadas.

Nesse sentido, Alvarez aponta:

el patrimonio cultural no es un hecho dado, una realidad que exista por si misma sino que es una construcción histórica, una concepción y una representación que se crea a través de un proceso en el que se 
intervienen tanto los distintos intereses de clases y grupos sociales que integran a la nación, como las diferencias históricas y políticas que oponen a los países. (ALVAREZ, 2012, p. 12)

Um dos principais conceitos utilizados para o termo "patrimônio" é o de legado pelo passado ou algo que se pretende conservar. Nesse mesmo contexto, é possível fazer a relação com os saberes culinários, que aplicados às memórias e aos costumes dos imigrantes, traduzem um dos principais elementos que constituem a gastronomia típica: o elo cultural (HERNANDEZ, 2005).

No ano de 1989, a UNESCO lançou uma cartilha ampliando o debate sobre Patrimônio Cultural. Nessa cartilha, o Patrimônio Cultural Imaterial pode ser definido como a manifestação patrimonial da porção intangível da herança cultural dos povos, incluindo as tradições, o folclore, as línguas, as festas e outras manifestações, citando como parte desses bens a gastronomia. Dessa forma considerando que a alimentação é um fator importante na identificação de uma sociedade, ela pode ser apontada como Patrimônio Cultural Imaterial (UNESCO, 1989).

Nas últimas décadas, o IPHAN, órgão responsável pelo tombamento dos bens culturais materiais e imateriais do Brasil, tem olhado para as tradições imateriais e costumes populares com outros olhos. Um exemplo é que diversos saberes populares e alguns patrimônios alimentares foram reconhecidos com o tombamento. Como exemplos, Gimenes-Minasse cita:

Dentre os bens já registrados como Patrimônio Imaterial, pode-se citar a Arte Kusiwa dos Índios Wajãpi, o Samba de Roda do Recôncavo Baiano, o Círio de Nossa Senhora de Nazaré, o Frevo, a Cachoeira do Iauaretê (lugar sagrado dos povos indígenas dos Rios Uaupés e Papuri), a Feira de Caruaru, o modo de fazer Viola-de-cocho e o Jongo do Sudeste, além do Ofício das Paneleiras de Goiabeiras, o Ofício das Baianas do Acarajé e, mais recentemente, o Modo Artesanal de fazer Queijo de Minas, nas regiões do Serro e das serras da Canastra e do Salitre (GIMENES-MINASSE, 2013, p. 24).

Nesse sentido, é possível pensarmos em trabalhar com o patrimônio cultural trazido pelos imigrantes europeus para o Brasil, principalmente a gastronomia, como um atrativo turístico para fomentar a preservação da cultura alimentar nos grupos étnicos, assim como uma forma de geração de renda para as comunidades receptoras. 


\title{
GASTRONOMIA POLONESA
}

A gastronomia de um grupo que reside em um determinado território é construída a partir da materialidade de quais alimentos são produzidos nessa região, da forma pela qual são preparados, da potencialidade de conservação e da disponibilidade de ferramentas para sua reprodução.

Desse modo, a gastronomia polonesa é formada por inúmeros pratos com os mais variados insumos e métodos de preparos. Sua base é constituída pela variedade de carnes, massas, cereais e legumes que são encontrados no leste europeu ou foram trazidos e incorporados à cultura alimentar polonesa (PISARSKI JUNIOR, 2019).

A necessidade de ter uma alimentação mais robusta em uma região geográfica caracterizada pela sua baixa temperatura e particularidades agrícolas fez com que a culinária polonesa tivesse sua base em alimentos mais adaptáveis para a região. Em uma tentativa de caracterizar isso, aponta-se:

\begin{abstract}
A culinária polonesa é rica em carne de todos os tipos e temperos, bem como de tipos diferentes de massas e bolinhos, sendo o mais popular deles o pierogi. Assemelha-se à outras culinárias eslavas quanto ao uso de mingaus (kasza) e de outros cereais. O clima frio do país favorece uma cozinha contundente na qual as carnes e as batatas são ingredientes essenciais (ADAMOSKI; KRIEGER, 2013, p. 12).
\end{abstract}

O conhecimento empírico do manuseio e dos métodos aplicados aos insumos alimentares permitiu que a gastronomia polonesa se desenvolvesse e pudesse criar uma grande variedade de pratos e preparos, como pode ser visto na tabela 1, baseado em Pisarski Junior (2019):

TABELA 1 - APRESENTAÇÃO E DESCRIÇÃO DE PRATOS E PREPAROS TÍPICOS POLONESES

\begin{tabular}{|c|c|}
\hline PRATO/PREPARO TÍPICO & DESCRIÇÃO \\
\hline PIEROGI & $\begin{array}{c}\text { Pastelzinho cozido (pode ser encontrado frito) } \\
\text { recheado com repolho, batata, cogumelos ou } \\
\text { embutidos. Também pode ser encontrado com } \\
\text { recheio de frutas. }\end{array}$ \\
\hline BIGOS & $\begin{array}{c}\text { Guisado de repolho (fresco e em conserva), } \\
\text { carnes suínas e/ou bovinas, cogumelos, temperos } \\
\text { e aromáticos. }\end{array}$ \\
\hline
\end{tabular}




\begin{tabular}{|c|c|}
\hline BARSZCZ & $\begin{array}{c}\text { Sopa à base de beterraba, carnes, batata e pode } \\
\text { ser encontrado também com repolho e/ou ovo. } \\
\text { Geralmente consumido com limão e/ou nata. }\end{array}$ \\
\hline GOŁĄBKI & $\begin{array}{c}\text { Charuto de carne moída (tanto bovina quanto } \\
\text { suína), arroz e temperos, envolvidos em folhas } \\
\text { de repolho. Geralmente servido com molho } \\
\text { vermelho. }\end{array}$ \\
\hline KIEŁBASA & $\begin{array}{c}\text { Linguiça polonesa, é o embutido clássico } \\
\text { da região feito à base de carne suína, alho e } \\
\text { temperos, mas também pode ser encontrado } \\
\text { mesclado com carne bovina e outros aromáticos. }\end{array}$ \\
\hline CHLEB & $\begin{array}{c}\text { Broa polonesa, pão à base de farinha de centeio, } \\
\text { banha (ou óleo), ovo, sal e levedura. Geralmente } \\
\text { é produzido em formato redondo ou retangular. }\end{array}$ \\
\hline PĄCZEK & $\begin{array}{c}\text { Sonho polonês, feito de massa doce frita e com } \\
\text { recheio de nata, doces de frutas e geleias da } \\
\text { região. }\end{array}$ \\
\hline
\end{tabular}

FONTE: Pisarski Junior (2019).

Embora esses pratos e preparos sejam considerados parte da gastronomia típica polonesa, muitos deles são encontrados e compartilhados com grupos étnicos-culturais vizinhos como ucranianos, russos, tchecos, alemães e lituanos, apesar de geralmente haver algumas variações entre outros grupos.

\section{FIGURA 1 - PIEROGI}

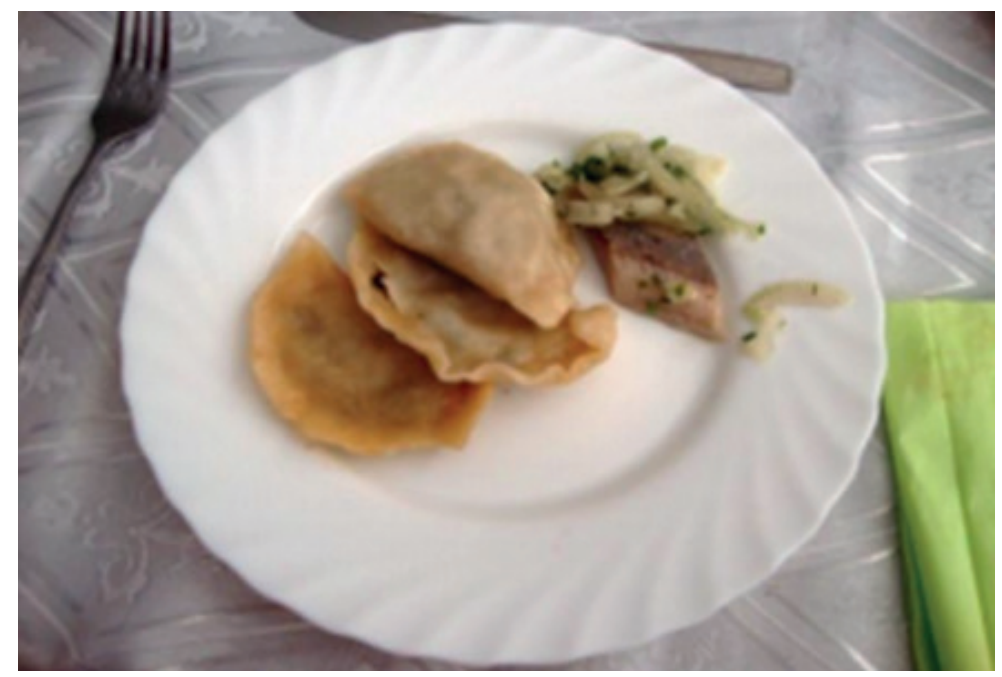

FONTE: TELEGINSKI, 2016. 
Na região de Curitiba, foco desta pesquisa, é possível notar-se a existência da reprodução e consumo de alguns desses pratos e preparos típicos. O maior exemplo é o caso do pierogi, apresentado na FIGURA 1, prato típico polonês apontado como símbolo da identidade cultural dos poloneses, conforme considera Teleginski:

Trata-se de um dos pratos mais populares na Polônia sendo considerado um símbolo nacional. Está difundido nas áreas de imigração polonesa do Paraná, Santa Catarina e Rio Grande do Sul. É um prato emblemático na Polônia e emblemático nas áreas de imigração polonesa no Brasil e países que receberam imigrantes poloneses como Estados Unidos, Canadá e Argentina, representando um forte símbolo de identidade étnica e regional (TELEGINSKI, 2014, p. 10).

Por esse caminho, as tradições culinárias étnicas representam muito mais que apenas os saberes do imigrado, mas também toda a história, geografia e cultura de um povo, que são trazidas na alma do imigrante.

Dessa forma, considera-se o ato de alimentar-se um componente central em uma cultura e não apenas uma forma de saciar a fome. Nesse sentido, Barbosa afirma:

o ato de comer está entre o que é natural e o que é social/cultural no homem, pois para sua sobrevivência é indispensável o alimento, que por sua vez, é utilizado e adaptado de acordo com os hábitos e costumes praticados em seu meio (BARBOSA, 2012, p. 2).

Dessa maneira, é necessário observar a gastronomia através de outro prisma, o do patrimônio cultural. Algo imaterial, mas que carrega a essência do povo, seus costumes e tradições. Além disso, também é preciso debater qual a função das burocracias no tombamento de bens históricos e suas relações.

\section{APONTAMENTOS TURÍSTICO-CULTURAIS E GASTRONÔMICOS}

A cidade de Curitiba e sua região (e consequentemente o estado do Paraná), como agentes envolvidos no contexto da imigração europeia, têm, em seus dias atuais, reflexos da etnicidade em seus âmbitos sociais e culturais. Com essa diversidade de culturas, existem diversas potenciais ofertas turísticas para serem exploradas que necessitam de mais atenção.

No sentido de explorar esses elementos culturais do turismo, Bizinelli, Manosso, Gimenez-Minasse e Souza afirmam: 
O turismo deixa então de ser observado como uma atividade de simples contemplação, para ser percebido como um componente que propicia a integração do turista em culturas diversas, oferecendo-lhes novas e memoráveis experiências (BIZINELLI; MANOSSO; GIMENEZMINASSE; SOUZA, 2014, p. 7).

Dentre essas experiências, a culturalidade transmitida pelo consumo de um prato típico pode ganhar extrema relevância quando explorado de maneira assertiva em conjunto com o turismo cultural.

Dentro desse cenário, a etnia polonesa deixou um profundo legado cultural em Curitiba, possibilitando estabelecer uma relação entre a gastronomia e os legados culturais dos imigrantes e seus descendentes como potenciais atrativos turísticos.

Isso contribui para os debates a respeito do legado étnico e do turismo nas últimas décadas, auxiliando no desenvolvimento do turismo gastronômico como parte integrante de um sistema turístico, o SISTUR.

Beni faz a classificação do segmento de serviços da gastronomia como um atrativo turístico "histórico-cultural", na conceituação do seu ambiente do sistema de turismo SISTUR, além de apontá-la como integrante do segmento de turismo cultural (BENI, 1998).

Bahl, por outro lado, afirma que um legado étnico por si só não se configura como um atrativo turístico. Porém, caso interligado à elaboração de um roteiro gastronômico, à adequação à lógica do turismo da cidade e aliado a outros elementos culturais, tem o potencial de transformar o legado étnico cultural em um produto turístico que pode beneficiar a comunidade receptora (BAHL, 2014).

Dessa forma, pode-se afirmar que o turismo cultural aliado à gastronomia étnica, além de fazer a manutenção de uma tradição cultural, pode ainda potencializar a visitação à cidade enquanto destino gastronômico.

Mascarenhas, ao pontuar sobre os potenciais do uso da gastronomia típica como mecanismo de preservação cultural, considera que:

\footnotetext{
o uso turístico da culinária típica pode ser uma das formas de preservála e de preservar sua cultura, uma vez que essa tradição culinária vem ao longo dos anos deixando de ser passada para as novas gerações. Nota-se que, com o ritmo de vida imposto pela sociedade atual, a herança culinária tradicional da localidade está sendo substituída por outras formas de alimentação (MASCARENHAS, 2009, p. 97).
} 
Nesse sentido, Schlüter afirma que a gastronomia típica como um atrativo turísticocultural pode ser interessante tanto para a população local quanto para os turistas, pois com a gastronomia as pessoas podem ter em seu imaginário a intenção de tentar entender a cultura de um lugar ou povo (SCHLÜTER, 2003).

Além de carregar esses elementos subjetivos, a gastronomia favorece a competitividade de um destino turístico como aponta a Organização Mundial do Turismo (OMT, 2012) em relatório técnico, onde afirma que cada vez mais o turista busca por experiências gastronômicas: "Thus, more and more tourists in the world are looking for concrete learning experiences, and in this endeavour the gastronomic experience".

De forma a complementar, ao analisar os potenciais do turismo gastronômico, Gândara (2008) questiona a competitividade entre destinos turísticos e aponta que oferecer diferenciais como roteiros gastronômicos pode ser importante para a fidelização de turistas.

Um exemplo clássico disso em Curitiba é o polo gastronômico de Santa Felicidade, que atrai centenas de turistas que passam pela cidade diariamente. Esse local utiliza a identidade cultural italiana como um atrativo turístico. A respeito da importância desse polo gastronômico para Curitiba, Kluge afirma:

\begin{abstract}
A comida típica de Santa Felicidade, apesar de não ser mais idêntica à italiana, porque foi modificada ao longo do tempo, é reconhecida como original deste Vêneto idealizado. Teria sido elaborada com o apoio da memória e no gosto culinário dos imigrantes, transmitida oralmente aos descendentes. Gradativamente, pratos de origem diversas foram sendo anexados ao cardápio desses restaurantes como a maionese - desconhecida entre os imigrantes italianos -, o rodízio de carnes e as massas de outras regiões da Itália: como a lasanha, o canelone e o nhoque. De forma que houve uma troca de hábitos alimentares, os italianos "abrasileirando-se" e os curitibanos "italianizando-se". (KLUGE, 1996, p. 111)
\end{abstract}

Observando a importância social e cultural do polo gastronômico de Santa Felicidade em Curitiba - PR, é possível apontar a possibilidade de utilizar essa mesma proposta com outras etnias, como a polonesa por exemplo, na formação de novos espaços como esse.

Nesse sentido, Poulain (2008) aponta que o patrimônio cultural alimentar é um elemento que pode contribuir para a valorização turística de uma região, sendo possível fazer com que o uso desse elemento ressignifique um espaço, utilizando-o de outra forma.

Desse modo, a questão econômica e, consequentemente, o desenvolvimento 
regional são aspectos que mostram o potencial do uso turístico de tradições alimentares relacionadas à cultura regional, como pode ser observado no exemplo apresentado por Feder a respeito do polo gastronômico de Santa Felicidade:

Estima-se que são servidas 160 mil refeições/mês para um público misto de $54 \%$ de curitibanos, $18 \%$ de paranaenses de outras localidades, $25 \%$ de brasileiros de outros estados e 3\% de estrangeiros. Segundo os dados da ACIFS (Associação do Comércio e Indústria de Santa Felicidade), os principais restaurantes da região geram em torno de 1500 empregos diretos e um faturamento mensal estimado de R $\$ 5,1$ milhões. (FEDER, 2005, p. 127)

A utilização da gastronomia típica dos imigrantes que tiveram influência em uma localidade como parte de um legado étnico deixado por eles pode ser considerada, portanto, um atrativo turístico que busca fortalecer uma identidade cultural e trazer retorno financeiro para a comunidade receptora.

\section{CONSIDERAÇÕES FINAIS}

Com a exposição dos elementos que constituem a imigração do grupo étnicocultural dos poloneses, seu legado cultural, apresentação da sua culinária e o apontamento da possibilidade de como utilizar esse patrimônio cultural para o fomento da preservação cultural e desenvolvimento regional das comunidades receptoras, é possível tornar palpável a potencialidade de se trabalhar com as tradições alimentares desse grupo como um novo produto turístico cultural na região de Curitiba - PR, a fim de promover e preservar a cultura da etnia polonesa e contribuir para o resgate da história e memória dos imigrantes.

Esse processo pode incluir a realização de roteiros perpassando pelas regiões de chegada e fixação da comunidade polonesa, e seguindo para regiões como as colônias de Araucária (PR) e de São José dos Pinhais (PR), onde a comunidade polonesa que vive em área rural ainda mantém algumas tradições fortes.

Essa ideia pode ser interessante ao turista pois ele poderá conhecer como se dá a manutenção da tradição alimentar, das comensalidades e da cultura como um todo para esse grupo étnico tão importante para a região, também incentivando e contribuindo para o desenvolvimento regional.

Pode-se ter como um exemplo de sucesso o forte roteiro que trabalha com a identidade cultural italiana na margem da cidade de Curitiba (PR), no bairro de Santa 
Felicidade, mostrando que, materialmente, é possível utilizar as tradições alimentares étnicas como produto turístico.

Para além disso, também é necessário buscar outros métodos de desenvolver o turismo cultural baseado na cultura polonesa na cidade de Curitiba - PR, podendo se basear no legado histórico desse grupo, seu folclore, a religiosidade e o legado artístico regional. 


\section{REFERÊNCIAS:}

ADAMOSKI, T.; KRIEGER, C. Comer para lembrar a alimentação e a preservação da identidade étnica polonesa nas colônias murici e mergulhão. Caderno de estudos e pesquisa do turismo, Curitiba, v. 2, p. 80-106, 2013.

ALVAREZ, M. La cocina como patrimonio (in)tangible. In: MARONESE, Leticia. (Org.). PRIMERAS JORNADAS DE PATRIMONIO GASTRONÓMICO, 2001, Buenos Aires. Primeras.... Buenos Aires: CPPHCCABA, 2005. p. 11-25.

BAHL, M. Legados étnicos \& oferta turística. Curitiba, Juruá. 2014.

BARBOSA, T. P. Antropologia e gastronomia: a identidade de ser brasileiro a partir da alimentação. In: SEMINARIO DO PROGRAMA DE PÓS- GRADUAÇÃO EM SOCIOLOGIA DA UFSCAR, 3., 2012, São Carlos-SP. Anais...São Carlos, SP, Brasil, 2012. Paginação irregular.

BENI, M. Análise estrutural do turismo. São Paulo: Senac. 2018.

BIZINELLI, C.; MANOSSO, F. F.; GIMENEZ-MINASSE, M. H. G.; SOUZA, S. do R. de. Enoturismo e Turismo de Experiência: novas possibilidades para a inclusão de pessoas com deficiência visual - Vinícola Dezem (Toledo, Paraná, Brasil). Revista Turismo e Sociedade, Curitiba, v. 7, n. 3, p. 495-522, 2014.

DOUSTDAR, N. M. Imigração polonesa: raízes históricas de um preconceito. 157 f. Dissertação (Mestrado em História) - Setor de Ciencias Humanas, Letras e Artes, Universidade Federal do Paraná, Curitiba, 1990.

DURAND, G. As estruturas antropológicas do imaginário. São Paulo: Martins Fontes. 2001.

FEDER, E. M. S. V. S. Santa Felicidade (Curitiba, Paraná): Através da polenta uma história de hospitalidade. 145 f. Dissertação (Mestrado em Pós-Graduação Stricto Sensu Turismo e Hotelaria) - Universidade do Vale do Itajaí, Balneário Camboriú, 2005.

GÂNDARA, J. M. G. Reflexões sobre o turismo gastronômico na perspectiva da sociedade dos sonhos. In: PANOSSO, A., N. \& ANSRAH, M. G. R. (Org.). Segmentação do mercado turístico: estudos, produtos e perspectivas. Barueri, São Paulo: Manole. 2008. p. 134-150.

GIMENES-MINASSE, M. H. S. G. Perfil dos eventos gastronômicos do estado do Paraná em 2001. In: BAHL, M. Turismo: Enfoques Teóricos e Práticos. São Paulo: Roca. 2013. p. 67-84. 
GIMENES-MINASSE, M. H. S. G. Cozinhando a tradição: festa, cultura, história e turismo no litoral paranaense. Curitiba: UFPR. 2013.

GLUCHOWSKI, K. Os poloneses no Brasil. Porto Alegre: Rodzicz \& Ordakowski. 2005.

HALL, M.; MITCHELL, R. Tourism as a force for gastronomic globalization and localization. In: HJALAGER, A. M.; RICHARDS, G. (Org). Tourism and Gastronomy. London: Routledge, 2013. p. 71- 90.

HERNANDEZ, J. C. Patrimônio e Globalização: o caso das culturas alimentares. In: CANESQUI, A.M.; GARCIA, R.W.D. Antropologia e Nutrição: um diálogo possível. Rio de Janeiro: Fiocruz, 2005

HOBSBAWN, E. A invenção das tradições (Introdução). In: HOBSBAWN, E. RANGER, T. A invenção das tradições. São Paulo: Paz e Terra. 2008. p. 12-20

IAROCHINSKI, U. Saga dos Polacos. Curitiba: Gráfica Mansão. 2000.

KLUGE, M. F. M. O Vêneto não pode morrer!: um estudo sobre restaurantes, rituais e (re) construção da identidade italiana em Santa Felicidade. 1996. 186 f. Dissertação (Mestrado em Antropologia Social) - Setor de Ciências Humanas, Letras e Artes, Universidade Federal do Paraná, Curitiba, 1996.

MACIEL, M. E. Identidade cultural e alimentação. In: CANESQUI A.M.; GARCIA. R.W. (Org.). Antropologia e nutrição: um diálogo possível. Rio de Janeiro: Fiocruz. 2005. p. 49-56

MASCARENHAS, R. G. T. A diversidade gastronômica como atrativo turístico na região dos Campos Gerais do Paraná: um estudo de caso no município de Castro. 333f. Tese (Doutorado em Geografia) - Setor de Ciências da Terra, Universidade Federal do Paraná, Curitiba, 2009.

OMT. Global report on food tourism. Madrid: Organização Mundial do Turismo (OMT). 2012.

PIRES, M. J. Prefácio. In: Fagliari, G.S. Turismo e alimentação: análises introdutórias. São Paulo: Roca. 2005. p. 4-7

PISARSKI JUNIOR, M.R.; SOUZA, S. do. R. de. A marginalização da cultura alimentar polonesa na região de Curitiba-PR. In: SIMPÓSIO INTERNACIONAL DE PATRIMÔNIO ALIMENTAR: os desafios e as delícias dos múltiplos saberes culinários, 2., 2018, Curitiba. Anais... Curitiba: PUCPR, 2018. p. 74-89. 
PISARSKI JUNIOR, M. R. Tradição alimentar polonesa e suas interfaces com o turismo no distrito de Colônia Murici, São José dos Pinhais/PR. 93 f. Dissertação (Mestrado em Turismo) - Setor de Ciências Humanas Universidade Federal do Paraná, Curitiba, 2019.

POULAIN, J. Los patrimonios gastronómicos y sus valorizaciones turísticas. In: TRESSERRAS, J.; MEDINA, F. (Eds.). Patrimonio gastronómico y, turismo cultural en el Mediterráneo. Barcelona: IBERTUR. 2008. p. 39-72.

SCARPATO, R. Gastronomy as a tourist product: The perspective of gastronomy studies. In: HJALAGER, A.; RICHARDS, G. (Ed.) Tourism and gastronomy. Londres: Ed. Routledge, 2002. p. 51-70.

SCHLÜTER, R. G. Gastronomia e Turismo. São Paulo: Aleph. 2003.

TELEGINSKI, N. M. Comeres, memórias e práticas: A transmissão da culinária polonesa entre descendentes de imigrantes no centro-sul do Paraná. In: Encontro Estadual de História da ANPUH-SP, 12., 2014, Santos. Anais eletrônicos....Sâo Paulo: ANPUH-SP, 2014. p. 22-38.

TELEGINSKI, N. M. Sensibilidades na cozinha: a transmissão das tradições alimentares entre descendentes de imigrantes poloneses no centro-sul do Paraná, século XX. 355 f. Tese (Doutorado em História) - Setor de Ciências Humanas, Universidade Federal do Paraná, Curitiba, 2016.

TURBANSKI, S. D. Murici, Terra Nossa. Curitiba: Amaro.1985.

UNESCO. Recomendação sobre a vanguarda da Cultura Tradicional e Popular. Unesco. 1989.

WACHOWICZ, R. C. História do Paraná. Curitiba: Vicentina. 1972. 